\title{
Water and Energy nexus: findings of the World Water Development Report 2014
}

\author{
MICHELA MILETTO \\ World Water Assessment Programme, Programme Office for Global Water Assessment, Division of Water Science, \\ UNESCO, Villa La Colombella, I-06134 Colombella, Perugia, Italy \\ wwap@unesco.org
}

\begin{abstract}
The post-2015 Sustainable Development Goals (SDG) are likely to include increased access to water and energy services. The fifth edition of the United Nations World Water Development Report (WWDR) Water and Energy aims to contribute to the this international process by informing the decisionmaking about the interlinkages, potential synergies and trade-offs as well as by stressing the need for appropriate responses and regulatory frameworks that account for both water and energy priorities. The Report provides a comprehensive and up-to-date overview of the impacts of ever-increasing energy production on water resources and water users, including agriculture, rapidly expanding cities, expanding industry and the environment. It analyses major and emerging trends from around the world, with examples of how some of the trend-related challenges have been addressed, their implications for policy-makers, and further actions that can be taken by stakeholders and the international community. As the first of a new series of theme-oriented reports to be released on an annual basis, the WWDR 2014 marks a pivotal new direction for the WWDR series, for the World Water Assessment Programme (WWAP), and the many partner agencies that contribute substantially in the production of the flagship report of UN-Water.
\end{abstract}

\section{INTRODUCTION}

"Water and energy are inextricably linked. Water is essential for the production, distribution and use of energy. Energy is crucial for the extraction and delivery of safe drinking water-and for the very safety of water itself. People everywhere - but especially the most vulnerable and marginalized - face great risks when access to either is limited or compromised" (Ban Ki-moon, WWDR 2014).

The fifth edition of the United Nations World Water Development Report (UN WWDR) Water and Energy, as the first of a new series of theme-oriented reports to be released on an annual basis, marks a pivotal new direction for the WWDR series, for the UN World Water Assessment Programme (UN WWAP, UNESCO) and the many partner agencies that work with WWAP in the production of the flagship report of UN-Water. Comprised of two volumes - the Report and an Annex with case studies/data-indicators - the 2014 edition provides a comprehensive and up-to-date overview of the impacts of ever-increasing energy production on water resources and water users, including agriculture, rapidly expanding cities, expanding industry and the environment, and of the constraints that water poses to energy developments. The Report provides a comprehensive overview of major and emerging trends from around the world, with examples of how some of the trend-related challenges have been addressed, their implications for policy-makers, and further actions that can be taken by stakeholders and the international community. It seeks to inform decision-makers, stakeholders and practitioners on the interconnections and interdependencies between the water and energy sectors.

The fact that the water and energy sectors are tightly interlinked means that choices made in one domain can have significant impacts in the other domain, carrying both positive and negative repercussions. The focus of the WWDR 2014 is on potential synergies and inevitable trade-offs to highlight the need for appropriate responses and regulatory frameworks that account for both water and energy priorities.

A number of Millennium Development Goals (MDGs) depend on major improvements in access to water, sanitation, power and reliable energy sources. In 2012, the United Nations Conference on Sustainable Development (Rio+20) explicitly acknowledged that water is at the core of sustainable development as it is closely linked to a number of key global challenges, and the United Nations General Assembly recognized the critical role that energy plays in the 
development process. Since energy and water remain the key for widespread poverty reduction, improving access to water and energy are already included in the discussion of the Sustainable Development Goals (SDGs) for the post-2015 agenda.

Freshwater and energy are crucial for human wellbeing and sustainable socio-economic development. They are often at the base of major regional and global crises. Water is required to produce, transport and use all forms of energy to some degree, and energy is required for the extraction, treatment and distribution of water. The form of energy production being pursued determines the amount of water required to produce that energy. At the same time, the availability and allocation of freshwater resources determine how much (or how little) water can be secured for energy production. Decisions made for water use and management, and for energy production, can have significant, multifaceted and broad-reaching impacts on each other - and these impacts often carry a mix of both positive and negative repercussions.

Although the two sectors are highly intertwined there are substantial differences: the different political economies of water and energy in particular should be recognized, as these affect the scope, speed and direction of change in each domain. While energy generally carries great political clout, and has virtually always been a private commodity, water resources have a long history of being considered as a public good, with access to safe water and sanitation being a human right.

Partly as a result, there is a marked difference in the pace of change in the domains; a pace which is driven also by the evolution of markets and technologies. Unless those responsible for water step up their own governance reform efforts, the pressures emanating from developments in the energy sphere will become increasingly restrictive and make the tasks facing water planners, and the objective of a secure water future, much more difficult to achieve. And failures in water can lead directly to failures in energy and other sectors critical for development.

\section{The challenge today: extending services to the un-served}

Currently, 768 million people lack access to an improved source of water, 2.5 billion remain without access to improved sanitation, 1.3 billion lack access to electricity and 2.6 billion use solid fuels for cooking, with its related negative health effects. These figures are often representative of the same people as evidenced by a close association between respiratory diseases caused by indoor air pollution, and diarrhoea and related waterborne diseases caused by a lack of safe drinking water and sanitation. Women and children, in particular, represent a disproportional fraction of those impacted.

\section{WATER FOR ENERGY: GROWING DEMANDS}

In line with the projected trends of population and economic growth, freshwater and energy demands are expected to continue to increase in the coming decades due to changing lifestyle such as increasing living standards and consumption patterns, technological development and government policy. Population growth and poverty reduction both lead to an increased water demand, reflecting growing needs for drinking water, health and sanitation, as well as for energy, food and other goods and services that require water for their production and delivery. Currently, an estimated $20 \%$ of the world's aquifers are already overexploited, and the deterioration of wetlands worldwide is reducing the capacity of ecosystems to purify water. Challenges will, however, be most acute in developing countries that undergo accelerated transformation and a rapid economic growth, or those countries in which a large segment of the population lacks access to modern services. These trends imply an increasing pressure on ecosystems and natural resources. In addition, climate change can exacerbate energy and water stress through events such as extreme weather conditions and prolonged drought periods.

Global water demand in terms of withdrawals is projected to increase by $55 \%$ towards 2050 (Fig. 1), mainly due to a growing demand from manufacturing (400\%), thermal electricity generation $(140 \%)$ and domestic use $(130 \%)$. As a result, freshwater availability will be increasingly strained over this time period, and more than $40 \%$ of the global population is projected to be living in areas of severe water stress by 2050. In the absence of sustainable 


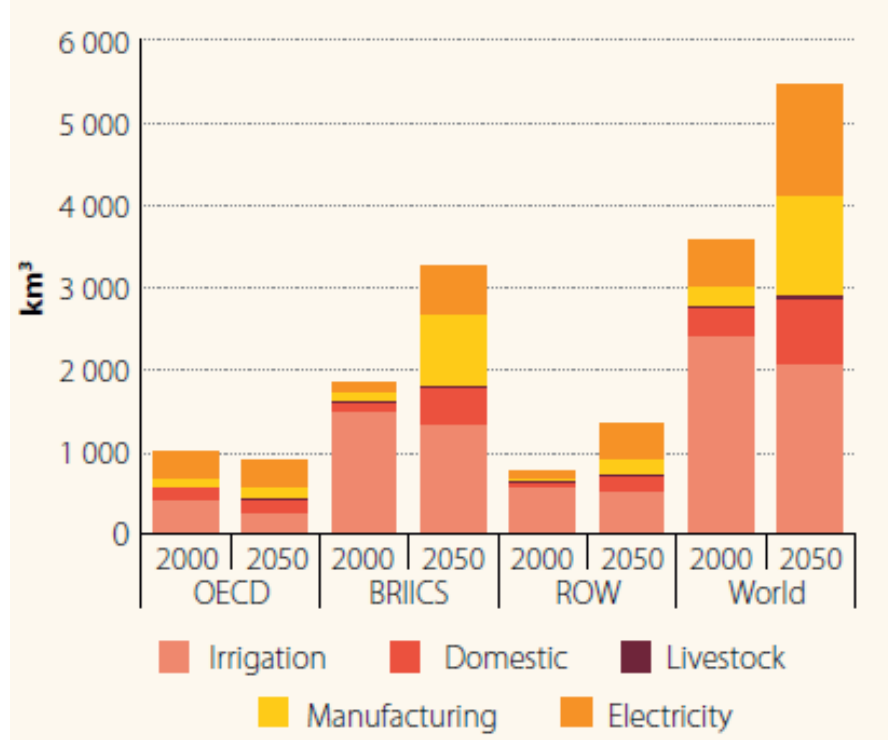

Fig. 1 Global water demand (freshwater withdrawals): Baseline scenario, 2000 and 2050. Note: BRIICS: Brazil, Russia, India, Indonesia, China, South Africa; OECD: Organisation for Economic Cooperation and Development; ROW: rest of the world. This graph only measures 'blue water' demand and does not consider rainfed agriculture. Source: WWAP 2014 (Fig. 2.1, p. 24,).

resources management practices, economic development can negatively impact water supplies in terms of quality and quantity. Meanwhile, global energy demand is expected to grow by more than one-third over the period to 2035 (China, India, and Middle East accounting for 60\%) with electricity demand growing by approximately $70 \%$ over the same time frame. This growth will be almost entirely in non-Organization for Economic Co-operation and Development (non-OECD) countries, with India and China accounting for more than half that growth.

Approximately $90 \%$ of global power generation is water intensive, where water is used either directly through hydropower generation or indirectly in the process of thermal power generation. For instance, $80 \%$ of global electricity is produced by thermal power plants, which are responsible for major water withdrawals for cooling. According to the International Energy Agency, global water withdrawal for energy production in 2011 amounted to 583 billion $\mathrm{m}^{3}$ of which 66 billion $\mathrm{m}^{3}$ was consumed. By 2035 , these figures could rise by respectively $20 \%$ and $85 \%$, the latter being due to higher efficiency power plants and increased biofuel production - being the most waterintensive type of fuel production it may cause substantial local and regional impacts. Moreover, it is predicted that water needs for energy production will grow at twice the rate of energy demand.

A continually growing demand and competition for limited water supplies increases the pressure on water intensive energy producers to seek alternative approaches. This growing scarcity creates an urgency to manage trade-offs and maximize co-benefits across multiple sectors. These restrictions also hold for the water sector. Given the fact that energy generally forms a substantial - if not the largest - expense for water and wastewater utilities, the cost and availability of energy will therefore have direct implications on availability as well as affordability of water in the rapidly growing cities of developing countries in the future.

In many countries, subsidies in water and energy are widespread and impose a large and growing fiscal burden. The majority of electricity and, in particular, water utilities charge tariffs substantially below levels commensurate with full cost recovery of operation and maintenance. Doing so causes unsustainable levels of energy consumption, and directly forms the cause of an unreliable and intermittent power supply together with its economic and social impacts. In addition, it may cause national power utilities to be loss making or even go bankrupt.

The International Energy Agency estimated global water withdrawals for energy production in 2010 at 583 billion $\mathrm{m}^{3}$ (representing some $15 \%$ of the world's total withdrawals), of which 66 billion $\mathrm{m}^{3}$ were consumed. Changes in the overall water availability might pose risks for the 
power sector due to a lack of cooling water, or due to insufficient availability to generate hydropower in dams. Unconventional oil and gas production, which is gaining momentum in some regions, is generally more water intensive than conventional oil and gas production. By 2035, withdrawals could increase by $20 \%$ and consumption by $85 \%$, driven via a shift towards higher efficiency power plants with more advanced cooling systems (that reduce water withdrawals but increase consumption) and increased production of biofuel.

Local and regional impacts of biofuels could be substantial, as their production is among the most water-intensive types of fuel production. Despite ongoing progress in the development of renewables, the overall evolution of the global energy mix appears to remain on a relatively fixed path: that of continued reliance on fossil fuels (Fig. 2).

Over $90 \%$ of global electricity generation is water intensive. Water is used in the extractive industries for producing fuels such as coal, uranium, oil and gas. Water is used directly for hydropower generation as well as for all forms of thermal power generation schemes that use heat to make power, which are responsible for roughly $80 \%$ of global electricity production. Water is an input for energy crops such as corn and sugar cane for ethanol and biomass for fuel pellets.

Power plant cooling is responsible for $43 \%$ of total freshwater withdrawals in Europe and nearly $50 \%$ in the United States of America.

From a water perspective, solar photovoltaic and wind are the most sustainable sources for power generation. The same accounts for geothermal energy. Although the latter technique is currently seriously underdeveloped, its potential is greatly under-appreciated given its near-zero greenhouse gas emissions, virtually zero water consumption and infinite availability at human time scales.

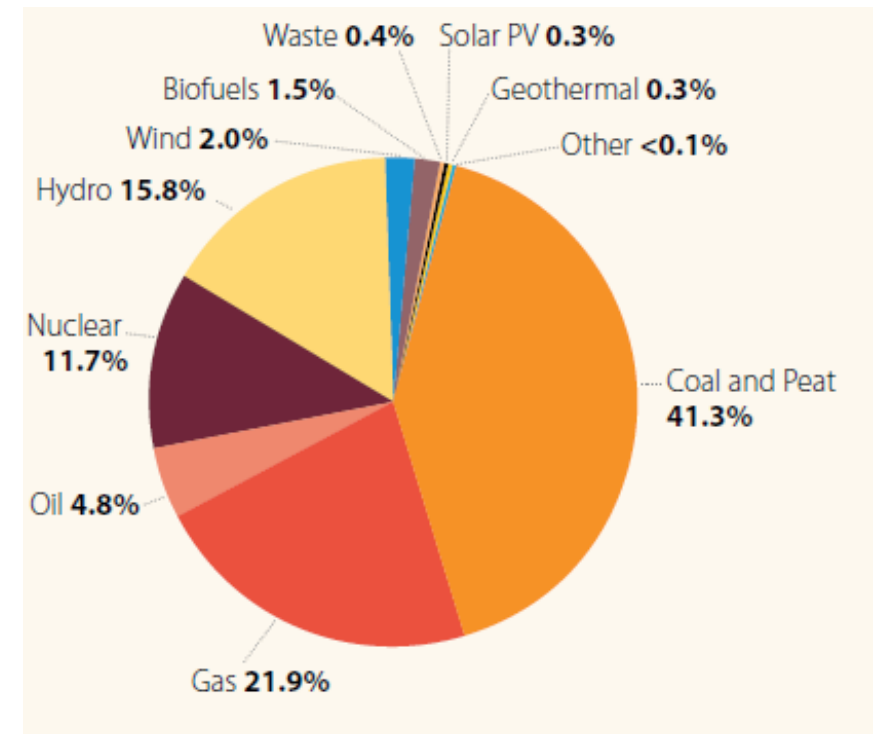

Fig. 2 World electricity generation by source of energy as a percentage of world electricity generation. Source: WWAP 2014 (Fig. 3.5, p. 34).

\section{ENERGY FOR WATER: THE OTHER SIDE OF THE NEXUS}

While more water will be needed to increase energy production, more energy will be necessary to extract, distribute and treat water resources. Energy is essentially required for pumping and treatment of water. Pumping the enormous quantities of water for irrigation requires large amounts of energy because of water's high density. The amount of energy needed for wastewater treatment processes varies greatly, depending on factors such as the quality of the source water, the nature of any contamination, and the types of treatment used by the facility; for instance, drinking water typically requires extensive treatment. Seawater desalination is very energy intensive for the requirements of reverse osmosis. 
Monitoring the availability and use of water resources currently forms an immense and ongoing challenge. The available water-use statistics are nowadays generally limited to gross water withdrawals without information on the net water consumption. This puts water resources management at a political disadvantage in terms of decision-making, making it hard to assess the impact of policy action at different levels on water resources.

\section{OPPORTUNITIES}

More than half of humanity currently lives in cities and the urban population is expected to increase rapidly, especially for cities of developing countries. Such rapidly growing cities are likely to be major hotspots for water and energy crises in the future. Besides consuming large quantities of water, cities also consume $60 \%$ to $80 \%$ of the commercial energy and emit about $75 \%$ of the greenhouse gases. A prerequisite for future urban development will be to take an approach of minimal resource consumption and to focus on resource recovery. In order to enable reaching of these goals, water and energy consumption may be significantly reduced through adequate urban planning during the early stages of development. This may be achieved through the construction of compact settlements and investments in Integrated Urban Water Management (IUWM), through measures such as water conservation, diversifying the source of supply, adjusting the degree of water treatment according to its end use, and the implementation of energy recovery measures.

Aside from generating water-savings through wastewater treatment and re-use, rainwater harvesting, and stormwater management, an array of opportunities exists to co-produce energy and water services and to exploit the benefits of synergies. Some examples of this are combined power and desalination plants, combined heat and power plants, using alternative water sources for thermal power plant cooling, and even energy recovery from the potential thermal and chemical energy present in sewerage water.

To kick-start these synergies, there is a need for new technological solutions and new political and economic frameworks to promote cooperation and integrated planning among sectors. To create coherent and compatible policy requires an enabling environment, including a hierarchy of actions: developing coherent national policies for different domains, creating legal and institutional frameworks to promote coherence, ensuring reliable data and statistics to monitor decisions, encouraging awareness through education, training and media, enhancing institutional capacity development, supporting innovation and research into technical developments, and allowing markets and businesses to develop.

In addition to this, it will be crucial to develop a higher degree of integrated planning and cooperation between the water and energy sectors on the level of policy-makers, planners and practitioners. Doing so could result in manifold benefits, the most important being to enhance the sustainable use of resources.

Part of the future investment required for both domains will be needed from private finance, which may be attracted by sound regulatory policies, public-private partnerships and result-based financing. Governments also need to cultivate widespread awareness of the water-energy nexus through public information fora, social and political discussions, and education. It is incumbent on professional communities in the water and energy domains to meet and dialogue with each other to a much greater extent than they do today.

The WWDR 2014 calls for a coordinated approach to water and energy. To achieve this, there is a need for generation and harmonization of data concerning the supply and use of energy production and water resources. The collection of such data and in general a more detailed set of water accounting statistics, describing different water uses within sectors, would facilitate decision-making and help ensure appropriate allocation of water resources. The same need exists regarding estimates of water consumption for different types of energy production. The development of robust water-energy indicators is crucial, as this knowledge is fundamental to ensuring energy security wherever water availability may be a limiting factor. To reach this goal, the international community needs to help strengthen the collectors and distributors of primary 
data in countries. Doing so may facilitate better public policy formulation, increase the visibility of co-benefits, and provide the basis for an open dialogue when difficult trade-off decisions need to be taken.

Applying water and energy efficiency measures may involve various trade-offs, which frequently involve short-term cost increases against long-term savings, an altered balance between water and energy use, and may require compromises in other fields such as labour, transportation, raw material costs and market location. In any case, applying energy efficiency measures in industries and communities often brings along savings through technological and behavioural changes.

Economic instruments to speed up reforms, but also to change user behaviour, may be diverse and may include taxes, pollution charges, subsidies, and markets for buying and selling the rights to use a resource or service. Economic pricing of energy and water services can more closely reflect the economic cost of their provision and therefore provide sufficient revenues for continued operation and maintenance.

\section{CONCLUSIONS}

The global community is aware of energy and water challenges, but has so far addressed them in isolation, within sectoral boundaries. Decision-makers need to consider broader influences and cross-sectoral impacts, strive for innovative policies and integrated institutions. If planned properly, water development and management programmes can serve multiple functions from contributing to both water and energy security and savings, to helping communities adapt to climate change. Sustainable policies should be based on sound technical, environmental and economic information addressing issues such as the availability and suitability of natural resources as well as socio-economic costs and benefits.

Institutions involved in policy formulation must be mindful of the water-energy nexus and incorporate it into their planning and decision-making systems. Institutional capacity development can play an important role in fostering interdisciplinary and inter-ministerial approaches that support the integration of interdependencies in decision-making through knowledge and technology transfers between different governmental levels and sectors, and through the exchange of case-specific experiences. For major infrastructures, integrated planning and the joint design of programmes and investments between energy and water experts and managers may be appropriate. There is a role for collaborative resource planning, identifying synergies and optimizing trade-offs. All such actions would be easier with a better mutual understanding of the economic gains to be had from collaboration and cooperation between the involved domains.

The links between water and energy production and ecosystems are manifold, and should be recognized. This may be realized through ways such as valuing natural infrastructure and paying for ecosystem services. In addition, correct economic pricing of energy and water services might be needed to more closely reflect the economic cost of their provision and to avoid waste and distortions due to under-pricing. Research into how much of a reduction in energy demand can be achieved from increased water efficiency and vice versa would support policy-makers and investors in making more resource efficient strategies and investment choices. The common aims of efficient use and reduction of wastage in the urban water and power services distribution sectors could be achieved by focusing on programmes to reduce unaccounted-for water, as water is a profligate user of energy. Legal and regulatory frameworks should be created to channel reforms and establish rules and sanctions for infractions by users. Calls for closer regulation and greater transparency, monitoring and local community engagement could all help to increase participation in the regulatory process.

Recognition of the interconnectedness between the water and energy sectors leads to a call for a greater level of integration of the two domains, and for finding synergies that create savings in both. The latter is fundamental to charting a course to a green economy. In this whole process of increasing the synergy between the water and energy sectors, the international community can play a key role by fostering transboundary cooperation, international trade and the development of 
regional energy grids and water distribution networks. These changes and innovations may contribute to reach the targets of overall economic progress, social equity and environmental protection.

\section{REFERENCES}

WWAP (World Water Assessment Programme) (2014) The United Nations World Water Development Report 2014: Water and Energy, vol.1, 151 pp. UNESCO, Paris. 